\title{
Solubilização de potássio em misturas de verdete e calcário tratadas termoquimicamente ${ }^{1}$
}

\author{
Vanessa Martins ${ }^{2}$, Ana Stella Freire Gonçalves ${ }^{3}$, \\ Giuliano Marchi ${ }^{4}$, Luiz Roberto Guimarães Guilherme ${ }^{3}$, Éder de Souza Martins ${ }^{4}$
}

\begin{abstract}
Potassium solubilization in verdete and limestone mixtures treated thermochemically

Brazil owns reserves of low solubility potassium silicate rocks, being necessary the development of alternative processing methods to increase their solubility, so they can be efficiently used in agriculture. This study aimed to get new technological routes to produce alternative potassium sources from verdete. Calcination and alkaline solubilization tests were performed for verdete and limestone mixtures. The calcination process followed by cooling at room temperature provided a higher potassium availability than other methods used. However, the increase of limestone content, concerning verdete, decreased the potassium solubility. The treatment limestone:verdete, in the proportion of $0: 100$, after calcination at $800^{\circ} \mathrm{C}$ during one hour and then treated with $\mathrm{NH}_{4} \mathrm{OH}$, and in the proportion of $25: 75$, after calcination, release proportionally higher amounts of $\mathrm{K}$ than non-calcinated samples.
\end{abstract}

KEY-WORDS: Calcination; alkaline solubilization; alternative source of potassium.

\section{INTRODUÇÃO}

Atualmente, a adubação potássica de solos agrícolas brasileiros é realizada empregando-se sais solúveis em água, principalmente o cloreto de potássio $(\mathrm{KCl})$. Em virtude da pequena produção brasileira (7,60\% do consumo aparente), quando comparada à grande demanda interna pelo produto, o Brasil situa-se no contexto mundial como grande importador de fertilizante potássico, principalmente de países como o Canadá $(31,18 \%)$, Bielorrússia $(21,96 \%)$, Alemanha $(18,93 \%)$, Israel $(10,73 \%)$ e Rússia $(9,24 \%)$. Essa situação é agravada pela única

\section{RESUMO}

O Brasil dispõe de reservas de rochas silicáticas potássicas de baixa solubilidade, sendo necessário o desenvolvimento de alternativas de beneficiamento capazes de aumentar sua solubilidade, para o suprimento da demanda desse nutriente na agricultura. Este estudo objetivou a obtenção de novas rotas tecnológicas para a produção de fontes alternativas de potássio, a partir do verdete. Prepararam-se misturas de verdete com calcário, para as quais foram realizados testes de calcinação e solubilização alcalina. O processo de calcinação seguido de resfriamento à temperatura ambiente proporcionou maior disponibilidade de potássio que os outros métodos empregados. Porém, o aumento na proporção de calcário, em relação ao verdete, ocasionou diminuição na solubilidade do potássio. $\mathrm{O}$ tratamento calcário:verdete, na proporção 0:100, calcinado por uma hora a $800^{\circ} \mathrm{C}$ e tratado com $\mathrm{NH}_{4} \mathrm{OH}$, e na proporção $25: 75$, submetida à calcinação, liberam, proporcionalmente, maior quantidade de potássio que as misturas não calcinadas.

PALAVRAS-CHAVE: Calcinação; solubilização alcalina; fonte alternativa de potássio.

mina em operação no Brasil, localizada no Complexo Taquari-Vassouras, em Sergipe, que possui condições de produção somente até 2016 (Brasil 2013).

O Brasil dispõe de reservas de minerais potássicos de baixa solubilidade, especialmente na forma de rochas silicáticas, situadas em posições estratégicas, do ponto de vista geográfico (Martins et al. 2010). Porém, a utilização dessas fontes exige o desenvolvimento de rotas tecnológicas de transformação capazes de torná-las fontes eficientes de fertilizantes (Luz et al. 2010). Por outro lado, a utilização direta do pó de rochas silicáticas pode ser uma alternativa viável, em termos econômicos

1. Trabalho recebido em jan./2014 e aceito para publicação em jan./2015 (http://dx.doi.org/10.1590/1983-40632015v4527917).

2. Universidade Federal do Piauí (UFPI), Colégio Técnico de Bom Jesus, Bom Jesus, PI, Brasil.E-mail: nessaufla@yahoo.com.br. 3. Universidade Federal de Lavras (UFLa), Departamento de Ciência do Solo, Lavras, MG, Brasil. E-mails: anastellafreire@hotmail.com, guilherrm@dcs.ufla.br.

4. Empresa Brasileira de Pesquisa Agropecuária (Embrapa Cerrados), Brasília, DF, Brasil.E-mails: giuliano.marchi@embrapa.br, eder.martins@embrapa.br. 
e ecológicos, visto seu baixo custo de produção (Martins et al. 2007). Esses materiais, dependendo das características mineralógicas das rochas de origem, apresentam solubilidade mais lenta que os fertilizantes convencionais, porém, fornecem também outros macro e micronutrientes presentes em sua composição, e alguns desses materiais ainda possuem propriedades favoráveis para se elevar o pH do solo (Lapido-Loureiro \& Nascimento 2009).

A mineralogia, indicador do potencial de solubilidade dos minerais e da capacidade de liberação de K, é fator fundamental na seleção de rochas para aplicação direta ao solo (Lapido-Loureiro \& Nascimento 2009). Os silicatos de liberação muito lenta podem apresentar utilização limitada em aplicações diretas, necessitando de processos de beneficiamento mais energéticos para aumentar sua solubilidade (Leite 1985, Valarelli et al. 1993).

O verdete é uma designação regional para um conjunto de rochas areno-pelíticas e pelíticas de cor verde, presentes na Formação Serra da Saudade do Grupo Bambuí e formadas no final do Neoproterozoico, sendo que a porcentagem de $\mathrm{K}$ varia em $7-14 \%$ (Lima et al. 2007). A composição mineralógica é variável, dependendo das diferenciações das camadas, mas, em geral, apresenta os seguintes minerais, em ordem decrescente de abundância: glauconita, quartzo, clorita, caulinita, micas, feldspatos e minerais opacos (Lima et al. 2007, Toledo Piza et al. 2011). A cor verde típica dos verdetes deve-se à presença de glauconita, em especial devido ao $\mathrm{Fe}^{2+}$ que substitui cátions como $\mathrm{K}^{+}, \mathrm{Na}^{+}, \mathrm{Ca}^{2+} \mathrm{e} \mathrm{Mg}^{2+}$, na estrutura desse mineral (Lima et al. 2007). O potássio está presente na glauconita, nas micas e no K-feldspato. Contudo, a baixa solubilidade das rochas geralmente inviabiliza respostas tão eficientes quanto as esperadas pelo uso de adubos convencionais solúveis.

Assim sendo, tem-se buscado processos de tratamento que venham a incrementar a solubilização e agregar valor aos produtos derivados de rochas, como, por exemplo, o tratamento térmico das rochas. Esse tratamento tem como objetivo a destruição da estrutura cristalina dos minerais fontes de potássio, para a formação de compostos nos quais esse nutriente se encontre em uma forma mais disponível aos vegetais, ou a interação com outros reagentes, a fim de aumentar sua solubilidade.

Este trabalho objetivou a caracterização de rotas tecnológicas para a produção de fontes alternativas de potássio, utilizando-se métodos de solu- bilização alcalina e de calcinação de verdete, com e sem adição de calcário, com a finalidade de aumentar a solubilidade de K.

\section{MATERIAL E MÉTODOS}

O experimento foi realizado no período de 2011 a 2012, no laboratório de Química e Geologia da Universidade Federal de Lavras (MG). As amostras de verdete $(\mathrm{V})$ foram coletadas no município de Cedro de Abaeté, na região do Alto Paranaíba (MG), moídas, passadas em peneiras de $0,25 \mathrm{~mm}$ e misturadas com dois tipos de calcário (C): um contendo baixo teor de $\mathrm{Mg}$ ( $\mathrm{CaO} 52,84 \%$ e $\mathrm{MgO}$ $2,87 \%$, doravante denominado $\mathrm{CC}$ ), equivalente à classificação antiga de calcário calcítico $(\mathrm{PN}=$ $102,17 \%$, PRNT $=93,21 \%$ e ER $=91,23 \%$ ), e outro com alto teor de $\mathrm{Mg}(\mathrm{CaO} 35,92 \%$ e $\mathrm{MgO}$ $14,44 \%$, doravante denominado $\mathrm{CD}$ ), equivalente à classificação antiga de calcário dolomítico $(\mathrm{PN}=$ $106,25 \%, \mathrm{PRNT}=91,44 \%$ e ER $=86,01 \%$ ). Foram testadas as seguintes proporções: $75 \% \mathrm{C}: 25 \% \mathrm{~V}$; $50 \%$ C:50 \% V; $25 \%$ C:75 \% V; e $0 \%$ C: $100 \%$ V, com três repetições.

Após a homogeneização, metade da quantidade de cada mistura foi calcinada em mufla a $800^{\circ} \mathrm{C}$, por uma hora, e resfriada à temperatura ambiente, e a outra metade foi mantida in natura $\left(25^{\circ} \mathrm{C}\right)$. Essas amostras são doravante denominadas 800 e 25 , respectivamente. As concentrações de K nos calcários utilizados são apresentadas na Tabela 1 .

A quantificação de $\mathrm{K}$ diretamente nas amostras tratadas foi feita utilizando-se microscópio eletrônico de varredura (LEO EVO $40 \mathrm{XVP}$ ) com sistemas de microanálise de raios-X da Bruker (Quantax EDS e Software Espirit) (Tabela 2).

Outra rota avaliada foi a solubilização da amostra de verdete em solução básica, tanto das amostras in natura quanto calcinada, adicionando-

Tabela 1. Porcentagem de $\mathrm{K}_{2} \mathrm{O}$ solúvel dos calcários usados nas misturas (Lavras, MG, 2011/2012).

\begin{tabular}{lccc}
\hline & $\begin{array}{c}\% \mathrm{~K}_{2} \mathrm{O} \\
\text { total }\end{array}$ & $\begin{array}{c}\% \mathrm{~K}_{2} \mathrm{O} \\
\left(\mathrm{H}_{2} \mathrm{O}\right)\end{array}$ & $\begin{array}{c}\% \mathrm{~K}_{2} \mathrm{O} \\
\text { (ácido cítrico) }\end{array}$ \\
\hline $\mathrm{CC} 25{ }^{\circ} \mathrm{C}$ & 0,050 & 0,003 & 0,009 \\
$\mathrm{CC} 800{ }^{\circ} \mathrm{C}$ & 0,100 & 0,006 & 0,015 \\
$\mathrm{CD} 25{ }^{\circ} \mathrm{C}$ & 0,030 & 0,001 & 0,010 \\
$\mathrm{CD} 800{ }^{\circ} \mathrm{C}$ & 0,012 & 0,012 & 0,020 \\
\hline
\end{tabular}

CC: calcário calcítico; CD: calcário dolomítico; $25^{\circ} \mathrm{C}$ in natura e $800{ }^{\circ} \mathrm{C}$ nas misturas calcinadas. 
Tabela 2. Porcentagem de $\mathrm{K}_{2} \mathrm{O}$ das misturas de verdete quantificadas pela microscopia eletrônica de varredura com microanalisador EDS (Lavras, MG, 2011/2012).

\begin{tabular}{lccc}
\hline & \multicolumn{3}{c}{$\% \mathrm{~K}_{2} \mathrm{O}$} \\
\cline { 2 - 4 } Misturas* & $25{ }^{\circ} \mathrm{C}$ & $800{ }^{\circ} \mathrm{C}$ & $800{ }^{\circ} \mathrm{C} \mathrm{com}$ \\
& \multicolumn{3}{c}{ média \pm desvio padrão } \\
\cline { 2 - 4 } & $3,37 \pm 0,42$ & $4,21 \pm 0,56$ & $3,78 \pm 0,12$ \\
$75 \mathrm{CC}: 25 \mathrm{~V}$ & $4,09 \pm 0,11$ & $7,76 \pm 0,31$ & $6,97 \pm 0,38$ \\
50CC:50V & $5,96 \pm 0,51$ & $6,02 \pm 0,68$ & $7,69 \pm 0,35$ \\
25CC:75V & $4,73 \pm 0,48$ & $3,71 \pm 0,33$ & $3,80 \pm 0,48$ \\
$75 \mathrm{CD}: 25 \mathrm{~V}$ & $5,35 \pm 0,16$ & $5,29 \pm 0,23$ & $5,93 \pm 0,56$ \\
50CD:50V & $6,11 \pm 0,73$ & $6,38 \pm 0,39$ & $7,26 \pm 0,33$ \\
25CD:75V & $7,67 \pm 0,16$ & $8,29 \pm 0,46$ & $8,58 \pm 0,26$ \\
0CC:100V &
\end{tabular}

* Porcentagem de calcário calcítico (CC), verdete (V) e calcário dolomítico (CD); $25^{\circ} \mathrm{C}$ in natura e $800{ }^{\circ} \mathrm{C}$ nas misturas calcinadas.

-se $10 \mathrm{~mL}$ de $\mathrm{NH}_{4} \mathrm{OH}$ concentrado $(\mathrm{pH} \mathrm{14,1),} \mathrm{em}$ $2 \mathrm{~g}$ da amostra. A suspensão foi agitada por 1 hora, a $200 \mathrm{rpm}$, em agitador mecânico horizontal. As amostras foram secas ao ar livre e, em seguida, a solubilidade do $\mathrm{K}$ em água e em ácido cítrico foi realizada, tanto das amostras in natura (25T) quanto das amostras calcinadas (800T), as quais foram quantificadas levando-se em consideração a porcentagem solúvel por massa de verdete.

A composição mineralógica das amostras de verdete puro, misturado com o calcário in natura e calcinado, foi determinada por meio de difratometria de raios-X. As amostras foram maceradas e passadas em peneiras de $150 \mu \mathrm{m}$ e submetidas à difração de raios-X pelo método de lâminas em pó, em aparelho PW Phillips 1840, com ajuste angular
(20), utilizando-se a radiação cobalto $\mathrm{K} \alpha$ com filtro de níquel.

Após a preparação das misturas, em triplicatas, foi analisado o $\mathrm{K}$ solúvel em água e ácido cítrico a $2 \%$, por fotometria de chama (Brasil 2007). Os dados referentes ao $\mathrm{K}$ solúvel foram submetidos a análises de variância, por meio do programa estatístico Sisvar (Ferreira 2008). As médias dos resultados foram comparadas utilizando-se o teste de Scott-knott, a 5\%.

\section{RESULTADOS E DISCUSSÃO}

Os maiores valores de $\mathrm{K}$ solúvel em água foram obtidos a partir das misturas tratadas com $\mathrm{NH}_{4} \mathrm{OH}$, tanto para as misturas com CC quanto para $\mathrm{CD}$ (Figuras 1a e 1b). As porcentagens de $\mathrm{K}_{2} \mathrm{O}$ solúvel foram calculadas em relação à massa de verdete de cada mistura.

Quando comparado apenas o efeito de calcinação, não houve diferenças significativas no aumento do K solúvel em água, porém, quando associados a calcinação e os tratamentos com $\mathrm{NH}_{4} \mathrm{OH}$ (800T), nas misturas, obteve-se aumento significativo na solubilidade. Os maiores valores foram obtidos nas misturas $0: 100 \mathrm{~V}$ in natura e com $\mathrm{NH}_{4} \mathrm{OH}(25 \mathrm{~T})$, 25CC:75V e 50CC:50V (800T) e (25T), para ambas as misturas (Figura 1a).

$\mathrm{O}$ tratamento das misturas com $\mathrm{NH}_{4} \mathrm{OH}$ mostrou efeito positivo na liberação de potássio para a solução, principalmente quando foi associado com calcinação, visto que os maiores valores foram obtidos para $800 \mathrm{~T}$, com exceção do verdete puro (0C:100V). Isso pode ser explicado pelo efeito fun-
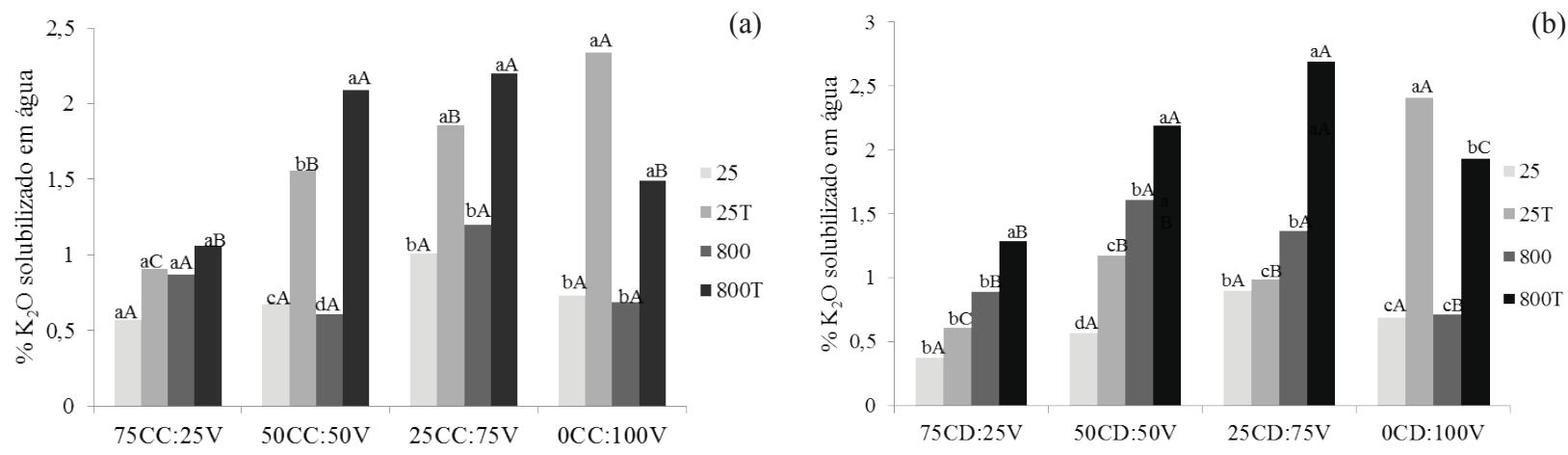

Figura 1. Porcentagem de $\mathrm{K}_{2} \mathrm{O}$ solúvel em água, em relação à massa de verdete em misturas com: (a) calcário calcítico (VCC) e (b) calcário dolomítico (VCD), tratadas (25T e 800T) e não tratadas com $\mathrm{NH}_{4} \mathrm{OH}(25$ e 800), calcinadas $(800$ e $800 \mathrm{~T})$ e in natura (25 e 25T) (Lavras, MG, 2011/2012). Letras maiúsculas referem-se à comparação das misturas nas diferentes temperaturas e tratamentos, e letras minúsculas referem-se à comparação dos diferentes tratamentos em cada mistura. Tratamentos com a mesma letra não diferem pelo teste de Scott Knott, a 5\%. 
dente dos carbonatos (Figura 1a), facilitando a quebra de estrutura dos minerais contidos no verdete. A mistura fundida, ao ser resfriada, transforma-se em vítrea e evita a recristalização do material fundido, isto é, torna-se amorfa, com as fases contendo K solúvel em água e ácidos fracos (Silva et al. 2012). Portanto, a presença de calcário possibilitou maior extração de $\mathrm{K}$, por auxiliar na transformação de fases. À medida que se aumenta o teor de $\mathrm{CaO}$, conhecido modificador da rede vítrea, aumenta-se, também, a quantidade de íons cálcio na estrutura vítrea do material, ou seja, as ligações Si-O-Si são quebradas pela introdução de íons $\mathrm{Ca}^{2+}$ na estrutura vítrea, tornando-a mais solúvel e aumentando, portanto, a disponibilidade de íons potássio (Chrissanthopoulos et al. 2008).

Comportamento semelhante foi obtido nas misturas de verdete e calcário com maior teor de magnésio (CD). Quando calcinadas e tratadas com $\mathrm{NH}_{4} \mathrm{OH}(800 \mathrm{~T})$, obtiveram-se aumentos significativos na liberação de K para a solução, destacando-se a mistura 25CD:75V (Figura 1b). Hellmann (1994), estudando a dissolução de feldspatos, encontrou forte evidência por dissolução não-estequiométrica a uma temperatura elevada, a $\mathrm{pH}$ básico.

Extratores ácidos, como, por exemplo, o ácido cítrico, são utilizados para quantificar a taxa de liberação de potássio nos minerais. Valarelli et al. (1993) e Castilhos \& Meurer (2001) reportam a ação desses ácidos na dinâmica de liberação de potássio de minerais, solos e suas frações granulométricas. Ácidos orgânicos de baixo peso molecular, como o ácido cítrico, podem facilitar a intemperização de minerais, pela formação de compostos nos quais o potássio encontra-se mais disponível (Silva et al. 2012).

A maior quantidade de $\mathrm{K}$ solúvel em ácido cítrico foi obtida em amostras calcinadas e sem tratamento com $\mathrm{NH}_{4} \mathrm{OH}$ (Figura $2 \mathrm{a}$ ), com exceção do verdete sem calcário, que apresentou $21 \%$ e $15 \%$ de $\mathrm{K}_{2} \mathrm{O}$ solubilizado, quando calcinado e pré-tratado com $\mathrm{NH}_{4} \mathrm{OH}$, respectivamente (Figuras $2 \mathrm{a}$ e $2 \mathrm{~b}$ ).

$\mathrm{O}$ teor de $\mathrm{K}$ solubilizado em ácido cítrico foi maior nas misturas de calcário com maior teor de cálcio que de magnésio, pois a calcita perde $\mathrm{CO}_{2} \mathrm{em}$ temperaturas mais baixas que a dolomita, havendo concentração de $\mathrm{K}$ na amostra. O cálcio diminui o ponto de fusão da mistura e não se recristaliza durante o resfriamento, pois a recristalização acarreta perda de solubilidade (Sanjad et al. 2004). Assim como verificado por Silva et al. (2012), que obtiveram 0,4\% de $\mathrm{K}_{2} \mathrm{O}$ extraído em ácido cítrico $1 \mathrm{~mol} \mathrm{~L}^{-1}$, em amostras de verdete in natura, e quando calcinado com acréscimo de $\mathrm{CaO}$, nas proporções de $10 \%, 20 \% \mathrm{e}$ $30 \%$, os teores de extração aumentaram consideravelmente para $6,4 \%, 7,7 \%$ e 4,2\%, respectivamente.

Para as misturas de verdete com $\mathrm{CD}$, os maiores valores de potássio solúvel em ácido cítrico também foram obtidos quando as amostras foram submetidas ao processo de calcinação sem pré-tratamento com $\mathrm{NH}_{4} \mathrm{OH}$, sendo maior na mistura 25CD:75V (Figura 2b).

No processo de calcinação, a temperatura de calcinação não foi suficiente para colapsar a estrutura dos minerais potássicos, apenas promovendo a desidroxilação da caulinita, isto é, a perda de água estrutural (Figuras 3a e 3b) (Menezes 2007).
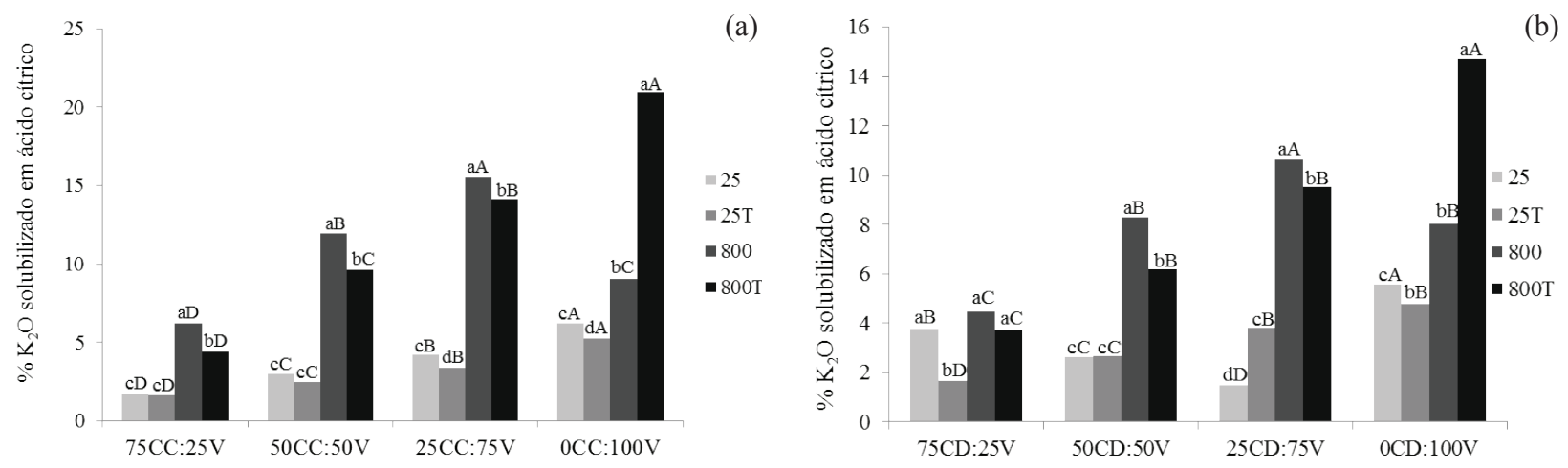

Figura 2. Porcentagem de $\mathrm{K}_{2} \mathrm{O}$ solúvel em ácido, em relação à massa de verdete em misturas com: (a) calcário calcítico (VCC) e (b) calcário dolomítico (VCD), tratadas (25T e 800T) e não tratadas com $\mathrm{NH}_{4} \mathrm{OH}$ (25 e 800), calcinadas (800 e $\left.800 \mathrm{~T}\right)$ e in natura (25 e 25T) (Lavras, MG, 2011/2012). Letras maiúsculas referem-se à comparação das misturas nas diferentes temperaturas e tratamentos, e letras minúsculas referem-se à comparação dos diferentes tratamentos em cada mistura. Tratamentos com a mesma letra não diferem pelo teste de Scott Knott, a 5\%. 


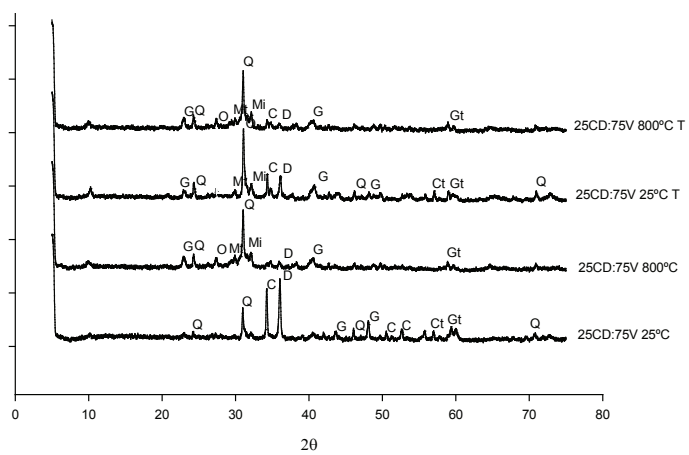

(a)

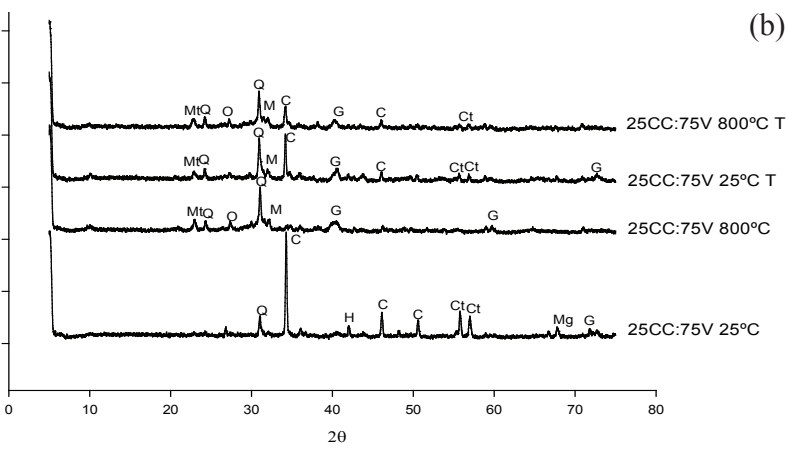

Figura 3. Difratogramas de raios-X (espaçamento em graus $2 \theta$ ) da mistura de verdete (75\%) com: (a) calcário dolomítico (25\%) e (b) calcário calcítico (25\%) (Lavras, MG, 2011/2012). G = glauconita; Gt = goethita; Q = quartzo; Mi = microclina; $\mathrm{O}=$ ortoclásio; $\mathrm{Mt}=$ montmorilonita $\mathrm{C}=$ calcita $\mathrm{Ct}=$ caulinita; $\mathrm{D}=$ dolomita; $\mathrm{Mt}=$ montmorilonita; $\mathrm{H}=$ hematita; $\mathrm{Mg}=$ magnetita.

O potássio presente na composição química do verdete pode ser atribuído à ocorrência de glauconita, caracterizada por ser um silicato lamelar hidratado de $\mathrm{K} \mathrm{e} \mathrm{Fe,} \mathrm{composto} \mathrm{por} 2$ folhas tetraédricas e 1 octaédrica, sendo que, na octaédrica, ocorre a substituição isomórfica de mais da metade dos íons $\mathrm{Al}^{3+}$ por $\mathrm{Fe}^{2+}$ (Gamero et al. 2004).

O processo de calcinação promoveu maior disponibilidade de sílica no mineral ortoclásio, pois ocorrem reações entre as bases dos carbonatos e os silicatos, mudando a estrutura vítrea do material, ou seja, as ligações Si-O-Si são quebradas pela introdução de íons $\mathrm{Ca}^{+2}$, tornando-a mais solúvel e aumentando a disponibilidade dos íons K (Figuras 3a e 3b). O pré-tratamento com $\mathrm{NH}_{4} \mathrm{OH}$ nas misturas dificultou o processo de fusão, na mudança de fase, com maior intensidade de pico da calcita e, ainda, presença da caulinita (Figuras 3a e 3b).

As misturas 50CC:50V e 50CD:50V calcinadas apresentaram maior intensidade nos picos de quartzo, montmorilonita e microclina e, a $25{ }^{\circ} \mathrm{C}$, a presença de caulinita apresentou maior intensidade no pico da calcita e, também, maior intensidade no pico da dolomita, para a mistura com CD (Figuras 4a e 4b).

Nesse processo, os minerais de baixa cristalinidade podem ser recristalizados em novos minerais hidratados, propiciando a formação de montmorilonita, que apresenta estrutura defeituosa, devido à substituição isomórfica dos átomos de $\mathrm{Mg}$ ou $\mathrm{Fe}$ por átomos de $\mathrm{Al}$ nos octaedros, e dos átomos de $\mathrm{Al}$ por átomos de Si nos tetraedros (Melo et al. 2002).

$\mathrm{O}$ pré-tratamento com $\mathrm{NH}_{4} \mathrm{OH}$, para essas proporções, também dificultou o processo de solubilização. Praticamente não houve diferenças nos espectros, apenas aumentando a intensidade dos picos da caulinita e, também, na mistura com $\mathrm{CC}$, aumentando o pico da calcita.

O aumento da proporção de calcário, em relação à do verdete $(3: 1)$, ocasionou diminuição na solubilidade de potássio, pois a maior quantidade de
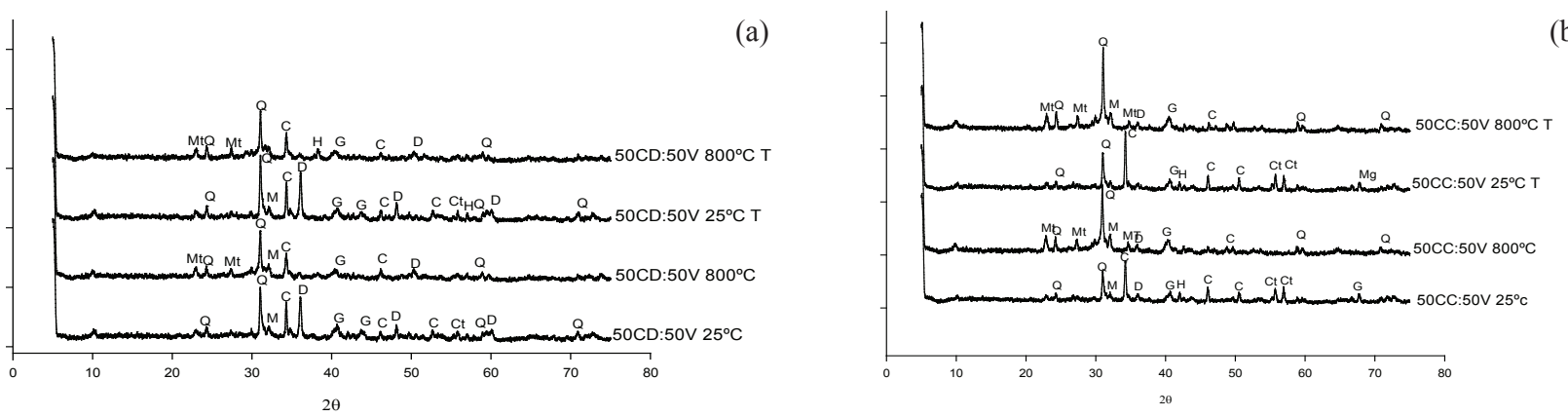

(b)

Figura 4. Difratogramas de raios-X (espaçamento em graus $2 \theta$ ) das misturas de verdete (50 \%) com: (a) calcário dolomítico (50 \%) e (b) calcário calcítico (50\%) (Lavras, MG, 2011/2012). G = glauconita; Q = quartzo; Mt = montmorilonita; $\mathrm{C}=$ calcita; $\mathrm{Ct}=$ caulinita; $\mathrm{M}=$ microclina; $\mathrm{H}=$ hematita; $\mathrm{Mg}$ = magnetita; $\mathrm{O}=$ ortoclásio. 

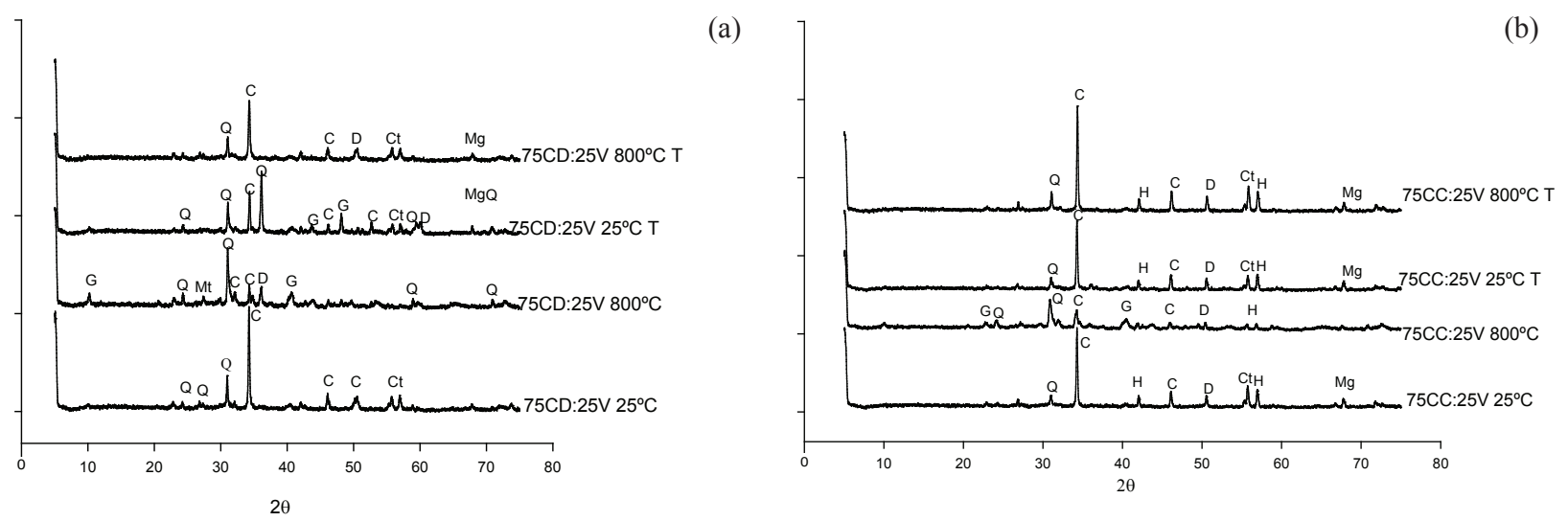

Figura 5. Difratogramas de raios-X (espaçamento em graus $2 \theta$ ) das mistura de verdete (25\%) com: (a) calcário dolomítico (75 \%) e (b) calcário calcítico (75 \%) (Lavras, $\mathrm{MG}, 2011 / 2012) . \mathrm{G}=$ glauconita; $\mathrm{Q}=$ quartzo; $\mathrm{C}=$ calcita; $\mathrm{Ct}=$ caulinita; $\mathrm{Mg}=$ magnetita; $\mathrm{H}=$ hematita.

carbonatos propicia diminuição na temperatura de queima e, com isso, o processo de calcinação não foi suficiente para a alteração de fases (Figuras 5a e 5b). A contribuição deles em teor de potássio é quase nula (Tabela 1), sendo que sua função nas misturas se restringe a promover a alteração de fase e, consequentemente, a liberação de $\mathrm{K}$ dos minerais contidos nas rochas.

Quanto maior a quantidade de calcita adicionada, a temperatura e o tempo de calcinação alcançados não foram suficientes para conseguir um equilíbrio termodinâmico, sendo que uma grande porção de $\mathrm{Ca}$ ficou sem combinação, o que pode ser constatado nos difratogramas 5a e 5b (Figura 5), pelos elevados picos de calcita.

O difratograma do verdete sem o calcário não apresentou diferença na composição química em nenhum dos tratamentos aplicados, porém, a maior quantidade de $\mathrm{K}$ solúvel foi observada a $800^{\circ} \mathrm{C}$, tratado com $\mathrm{NH}_{4} \mathrm{OH}$ (Figura 2a), provavelmente devido à semelhança dos raios iônicos, podendo o amônio deslocar o potássio dos sítios de troca no mineral (Figura 6).

$\mathrm{O}$ verdete é uma rocha potencial de $\mathrm{K}$, porém, pelos resultados de solubilidade apresentados, pode-se confirmar que são necessárias rotas tecnológicas para potencializar a disponibilidade do K presente no mineral, pois, tanto a rota de calcinação quanto a de solubilização alcalina promoveram modificações estruturais na rocha, que foram detectadas por difratometria de raios- $\mathrm{X}$.

\section{CONCLUSÕES}

1. O verdete in natura apresenta baixa solubilidade em água e em ácido cítrico, sendo que o processo

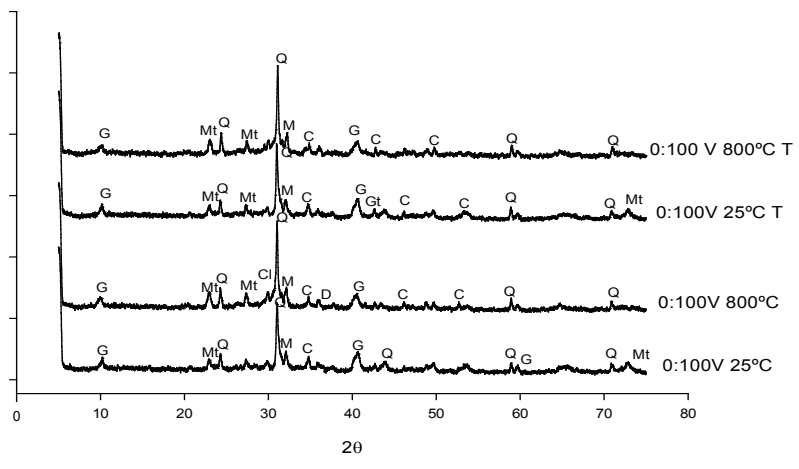

Figura 6. Difratogramas de raios-X (espaçamento em graus $2 \theta$ ) das amostras de verdete (Lavras, MG, 2011/2012). $\mathrm{G}=$ glauconita; $\mathrm{Q}=$ quartzo; $\mathrm{O}=$ ortoclásio; $\mathrm{Mt}=$ montmorilonita; $\mathrm{C}=$ calcita; $\mathrm{M}=$ microclina; $\mathrm{H}=$ hematita; $\mathrm{Mg}=$ magnetita; $\mathrm{D}=$ dolomita.

de calcinação proporciona maior solubilização de K.

2. O aumento da proporção de calcário, em relação à do verdete, ocasiona diminuição na solubilidade de $\mathrm{K}$.

3. $\mathrm{O}$ tratamento $0 \mathrm{C}: 100 \mathrm{~V}$ calcinado por uma hora, à temperatura de $800^{\circ} \mathrm{C}$ e tratado com $\mathrm{NH}_{4} \mathrm{OH}$, e a mistura $25 \mathrm{CC}: 75 \mathrm{~V}$ submetida à calcinação liberam maior quantidade de K para a solução (aumento de 3,4 e 3,7 vezes, em relação à amostra in natura, respectivamente).

\section{REFERÊNCIAS}

BRASIL. Departamento Nacional da Produção Mineral. Potássio. 2013. Disponível em: <https:// sistemas.dnpm.gov.br/publicacao/mostra_imagem. 
asp? IDBancoArquivArquivo=7404 $>$. Acesso em: 21 mar. 2013.

BRASIL. Instrução normativa $\mathrm{n}^{\circ} 28$, de 27 de julho de 2007. Aprova os métodos analíticos oficiais para fertilizantes minerais, orgânicos, organo-minerais e corretivos, disponíveis na Coordenação-Geral de Apoio Laboratorial - CGAL/SDA/MAPA, na Biblioteca Nacional de Agricultura - Binagri e no sítio do Ministério da Agricultura, Pecuária e Abastecimento. Diário Oficial da República Federativa do Brasil, Brasília, DF, 31 jul. 2007. Seção 1, p. 11.

CASTILHOS, R. M. V.; MEURER, E. J. Cinética de liberação de potássio em planossolo do Estado do Rio Grande do Sul. Ciência Rural, Santa Maria, v. 31, n. 6, p. 979-983, 2001.

CHRISSANTHOPOULOS, A.; BOUROPOULOS, N.; YANNOPOULOS, S. N. Vibrational spectroscopic and computational studies of sol-gel derived $\mathrm{CaO}-\mathrm{MgO}-$ $\mathrm{SiO}_{2}$ binary and ternary bioactive glasses. Vibrational Spectroscopy, Kidlington, v. 48, n. 1, p. 118-125, 2008.

FERREIRA, D. F. Sisvar: um programa para análises e ensino de estatística. Revista Symposium, Lavras, v. 6, n. 2, p. 36-41, 2008.

GAMERO, R. M. P.; TORRADO, P. V.; FERREIRA, T. O. Mineralogia e físico-química dos solos de mangue do Rio Iriri no canal de Bertioga. Revista Brasileira de Ciência do Solo, Viçosa, v. 28, n. 4, p. 233-243, 2004.

HELLMANN, R. The albite-water system: part I. The kinetics of dissolution as a function of $\mathrm{pH}$ at 100, 200, and 300 degrees C. Geochimica et Cosmochimica Acta, London, v. 58, n. 9, p. 595-611, 1994.

LAPIDO-LOUREIRO, F. E. V.; NASCIMENTO, M. Importância e função dos fertilizantes numa agricultura sustentável e competitiva. In: LAPIDO-LOUREIRO, F. E. V.; MELAMED, R.; FIGUEIREDO NETO, J. (Eds.). Fertilizantes: agroindústria e sustentabilidade. Rio de Janeiro: Cetem/Petrobrás, 2009. p. 81-132.

LEITE, P. C. Efeitos de tratamentos térmicos em misturas de verdete de Abaeté, fosfato de Araxá e calcário magnesiano, na disponibilidade de potássio e fósforo. 1985. 146 f. Dissertação (Mestrado em Agronomia) Escola Superior de Agricultura de Lavras, Lavras, 1985.
LIMA, O. N. B.; UHLEIN, A.; BRITTO, W. Estratigrafia do grupo Bambuí na Serra da Saudade e geologia do depósito fosfático de Cedro do Abaeté, Minas Gerais. Revista Brasileira de Geociências, São Paulo, v. 37, n. 4, p. 204-215, 2007.

LUZ, P. H. C. et al. Otimização da aplicação de corretivos agrícolas e fertilizantes. Informações Agronômicas, Piracicaba, v. 129, n. 1, p. 1-13, 2010.

MARTINS, E. S. et al. Materiais silicáticos como fontes regionais de nutrientes e condicionadores de solos. In: FERNANDES, F. R. C.; LUZ, A. B. da; CASTILHOS, Z. C. (Orgs.). Agrominerais para o Brasil. Rio de Janeiro: Cetem, 2010. p. 89-104.

MARTINS, E. S. et al. Rochas silicáticas como fontes minerais alternativas de potássio para a agricultural rochas e minerais industriais. Rio de Janeiro: Cetem, 2007.

MELO, V. F. et al. Mineralogia das frações areia, silte e argila de sedimentos do grupo Barreiras no município de Aracruz, Estado do Espírito Santo. Revista Brasileira de Ciência do Solo, Viçosa, v. 26, n. 1, p. 29-41, 2002.

MENEZES, R. R. et al. Utilização do resíduo do beneficiamento do caulim na produção de blocos e telhas cerâmicos. Revista Matéria, Rio de Janeiro, v. 12, n. 1, p. 225-235, 2007.

SANJAD, T. A. B. C. et al. Caracterização mineralógica de azulejos de Salvador e Belém dos séculos XVI, XVII e XIX. REM: Revista Escola de Minas, Ouro Preto, v. 57, n. 4, p. 255-260, 2004.

SILVA, A. A. S. et al. Verdete de Cedro do Abaeté como fonte de potássio: caracterização, tratamento térmico e reação com CaO. Revista Matéria, Rio de Janeiro, v. 17, n. 3, p. 1061-1073, 2012.

TOLEDO PIZA, P. A. et al. Verdete da região de Cedro do Abaeté (MG) como fonte alternativa para potássio. Geociências, São Paulo, v. 30, n. 3, p. 345-356, 2011.

VALARELLI, J. V. et al. Ardósias verdetes de Cedro do Abaeté na produção de termofosfato potássico fundido e sua eficiência agronômica. Anais da Academia Brasileira de Ciências, Rio de Janeiro, v. 65, n. 4, p. 343-375, 1993. 